
\title{
Southern Great Plains
} Newsletter

\section{Scientists Convene at SGP Site for Complex Convective Cloud Experiment}

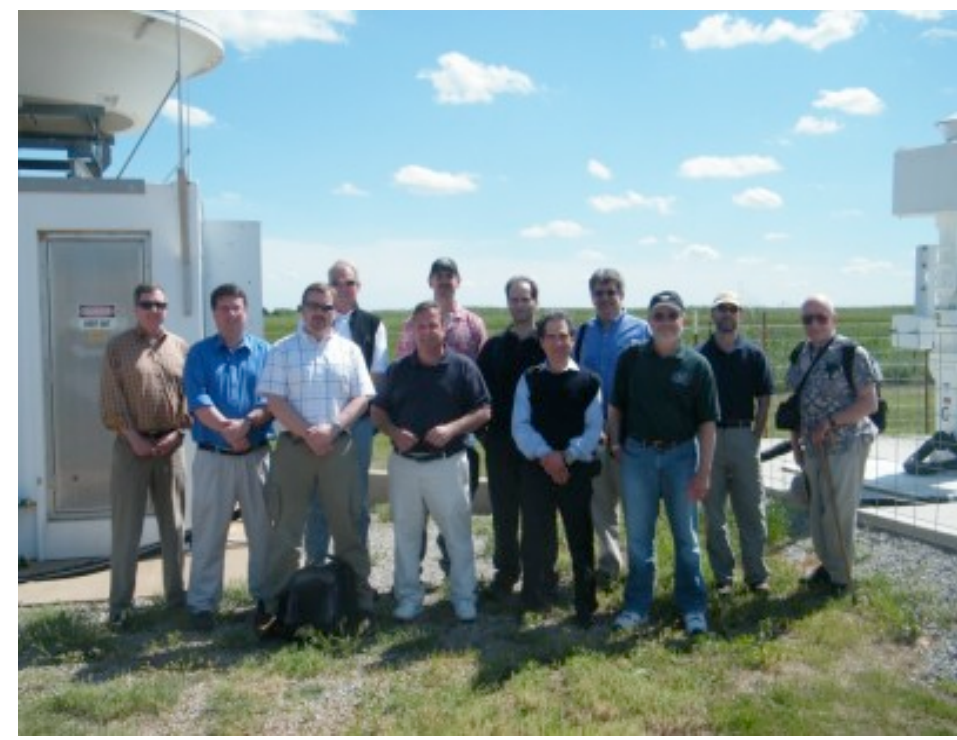

Photo courtesy of ARM

In early May, scientists involved in the Midlatitude Continental Convective Cloud Experiment (MC3E), a joint field program involving NASA Global Precipitation Measurement Program and ARM investigators, held their first onsite planning meeting to begin pinpointing the details for this major effort. Planned for April-May 2011 at the ARM Southern Great Plains site, the campaign is highly complex, involving five remote radiosonde sites, supplemental radars, coordinated aircraft, and a dense network of rain gauges and disdrometers. By heavily supplementing the routine measurements from the SGP site, the goal of MC3E is to provide the most complete characterization of convective cloud systems and their environment that has ever been obtained, providing details for the representation of cumulus clouds in computer models that have never before been available.
Gathering at the SGP site for the first day of the meeting, they reviewed the site's capabilities and additional equipment required for the campaign, focusing mainly on radar system operations. These include the existing ARM radars, the new ARM radar systems to be deployed later this year through the American Recovery and Reinvestment Act of 2009, and several additional NASA radar systems to be deployed for the campaign. They discussed siting logistics, scanning strategies, and how to best use all the systems together to accomplish the science goals of the campaign. The day ended with a visit to the future site of one of the ARM X-band radar systems that will play an important role in observing storm-scale dynamics during MC3E.

The next day, the group met in nearby Ponca City to further refine plans for the experiment. Discussions focused on the details and logistics of the radiosonde array, as well as aircraft instrumentation and operations. This included finalizing locations for radiosonde launch sites and aircraft weather briefings, staffing, and flight plans on the aircraft instrument payloads. For safety purposes, a plan was initiated for forecasting the presence of convective storms-the target of MC3E operations-and more severe weather events.
Special Interest

Articles:

- MC3E: Planning begins for Spring 2011 campaign

- VORTEX2: SGP lends a helping hand

- SPARTICUS: SAM provides validation

Individual Highlights:

$\begin{array}{ll}\text { VORTEX2 } & 2 \\ \text { DQ Office } & 2 \\ \text { SPARTICUS } & 3 \\ \text { Ceilometer } & 4 \\ \text { Dr. Kimpel } & 5 \\ \text { Activity } & 5\end{array}$




\section{VORTEX2 Spins Down}

Though research indicates that a tornado can form in a matter of minutes, the impact of its destruction can last a lifetime. A critical step toward developing a better warning system is to first determine exactly how tornadoes develop. With more than 100 scientists from over a dozen universities and several government and private organizations from around the world, including the ARM Southern Great Plains (SGP) site, VORTEX2 is the largest tornado research effort ever conducted. In collaboration with Matthew Parker, a professor in the Marine, Earth, and Atmospheric Sciences Department at North Carolina State University and the VORTEX2 mobile upsonde coordinator, ARM provided data for the campaign on May 10,11, 12, and 19 through the balloon-borne sounding system.

Sondes were launched on these days to gather atmospheric data when areas in Oklahoma and Kansas showed the potential for severe weather.

These data will be critical for helping scientists to understand the severe weather outbreak that began in
Oklahoma and Kansas on May 10. There were over 25 tornadoes in the area on that day, with significant property damage in central Oklahoma and numerous reports of high winds and large hail. Conditions calmed down on the 11th, although some severe storms formed in northwest Oklahoma, then picked up again on the 12 th, as severe weather, including a few tornadoes, spread over Oklahoma and up into Kansas. The 19th also saw widespread severe weather, again with tornadoes, mainly in central Oklahoma.

The campaign's goal is to develop improved storm predictions and reduce the threat that severe weather poses to life and property. This year's campaign represented the second season of collaboration between ARM and VORTEX2. The final leg of the VORTEX 2 campaign began on May 1 , 2010, and was completed on June 15, 2010. For more details about storm reports issued during the campaign, look for "Past Storm Reports" on the Storm Prediction Center website and enter the dates of interest.

\section{Happy Anniversary! ARM Data Quality Office Turns Ten}

"Everyone who works here at the $D Q$ Office is top notch!"
This June, the ARM Data Quality (DQ) Office celebrates its 10-year anniversary as the official gatekeeper of ARM data. Staffed by personnel from the University of Oklahoma, the DQ Office ensures quality data-the hallmark of the user facilityare collected by field instrumentation located at ARM's sites around the world.

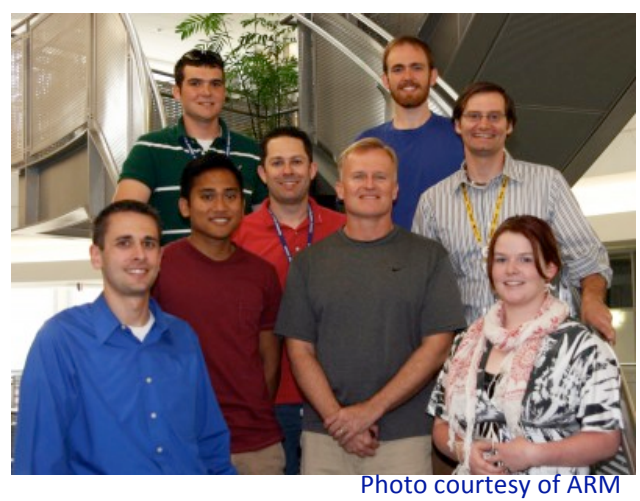

Over the past 10 years, the DQ office has grown from a staff of two to an office with four full-time staff members and five part-time OU students. "Everyone who works here at the DQ Office is top notch!" said Randy Peppler, ARM Data Quality Manager, and former member of the Southern Great Plains (SGP) site scientist team. "And the reason ARM data are valued so much by the scientific community." 


\section{Sunphotometer Supports SPARTICUS Campaign and Satellite Validation Studies}

To supplement airborne cirrus particle size measurements obtained during SPARTICUS, a Sun and Aureole Measurement (SAM) imaging sunphotometer is collecting groundbased radiance measurements at the ARM Southern Great Plains (SGP) site's Central Facility. Measurements of the solar disk and aureole radiance profile at a wavelength of $670 \mathrm{~nm}$ are ideally suited to investigate the larger droplets found in water and the smaller ice crystals found in cirrus clouds. Researchers leading the SAM Support for SPARTICUS campaign plan to apply a diffraction technique to the SAM profile measurements that, in previous studies, has yielded particle size distribution results in the 5 to 50 micron range. This is the size range of the "small" ice crystals of special interest in the SPARTICUS campaign.

With the extension of the SPARTICUS campaign into June, comparisons between the SAM and airborne measurements have not yet begun. However, comparisons of SAM measurements with MODIS satellite retrievals and with ARM Raman lidar and Cimel sun photometer measurements were reported in a poster at the first ASR Science Team Meeting in Bethesda, Maryland, in March. The data show excellent agreement between SAM and

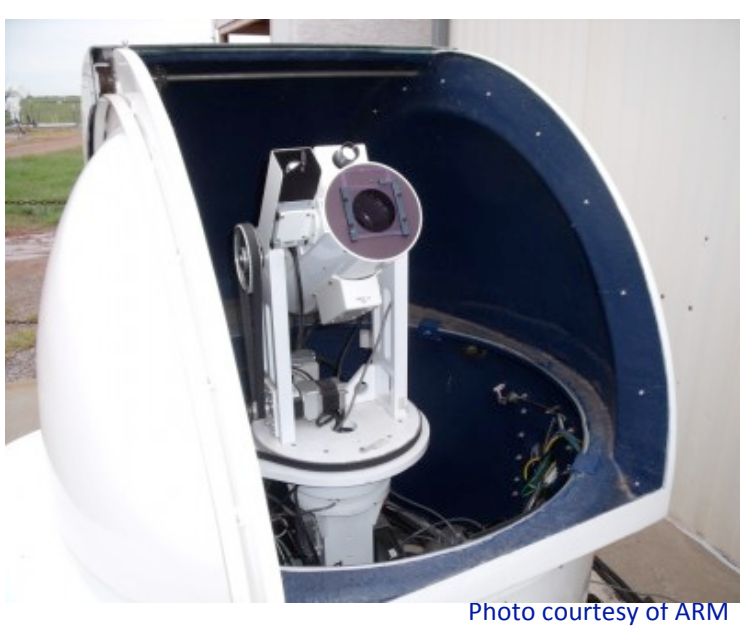

the Cimel photometer, and reasonable agreement with the Raman lidar given their different lines-of-sight. Satelliteretrieved parameters resulted in considerably dimmer solar disk radiances than measured by SAM. The aureole profiles also differed qualitatively, confirming the value of ongoing investigation into different treatments of ice crystal surface optical properties.

Once the SPARTICUS campaign ends, the SAM instrument will remain in place at the Central Facility and begin obtaining data for another campaign, Validation of MODIS Cirrus Algorithm Improvements. 


\section{$\square \square \square \square \square \square \square$ \\ Page 4 of 5 \\ SGP Newsletter \\ Ceilometer Represents First Deployment of New Ground- based Instruments from Recovery Act}

In April, a new ceilometer was deployed at the ARM Southern Great Plains site's Central Facility, leading the charge for an influx of more than 100 new groundbased instruments slated for installation throughout the user facility through the American Recovery and Reinvestment Act.

"We have a large number of instruments procured through the Recovery Act in various stages of development and testing, and a few are already installed and operating on a Learjet aircraft for the SPARTICUS campaign, but this is the first one that is now officially collecting routine ARM data. This is a very exciting time for us!" said Jimmy Voyles, an engineer at Pacific Northwest National Laboratory and the project lead for ARM's Recovery Act investments.

The ceilometer is designed to measure cloud-base height at up to three levels and potential backscatter signals by aerosols. It works by transmitting nearinfrared pulses of light into the sky. The receiver detects the light scattered back by clouds and precipitation.

The ceilometer is one of three instruments - the others being a present weather sensor and sunphotometer - that make up an integrated measurement suite known as the Boundary Layer Cloud System. Victor Morris, a scientist at PNNL, is overseeing the implementation of the system throughout the user facility.



"The combination of these three instruments was not available at each of the sites before the Recovery Act," said Morris. "Now we'll be able to provide consistency in the measurements from the ceilometers, sun photometers, and present weather sensors at all the ARM fixed and mobile sites to enhance the study of cloud formation processes and their influence on radiative transfer."

In use since 1994 , the CT25K model installed throughout the user facility was discontinued by the vendor in 2007 . The new CL31 provides increased spatial and temporal resolution, improved algorithms for cloud amount and mixinglayer height, and a modular design for easy field servicing. They have been configured to optimize the performance for aerosol and boundary-layer detection. The remaining new ceilometers will be shipped out for deployment at the other ARM sites.
"This is a very exciting time for us!" 
Technical Contact: Brad W. Orr

Phone: 630-252-8665

E-Mail: brad.orr@anl.gov

Editor: Jenni Prell

Contributor: Lynne Roeder

ACRF Southern Great Plains Newsletter is published by Argonne National Laboratory managed by Uchicago

Argonne, LLC, for the U.S.

Department of Energy under contract number DE-AC02-06CH11357.

\section{We're on the Web!}

See us at: www.arm.gov

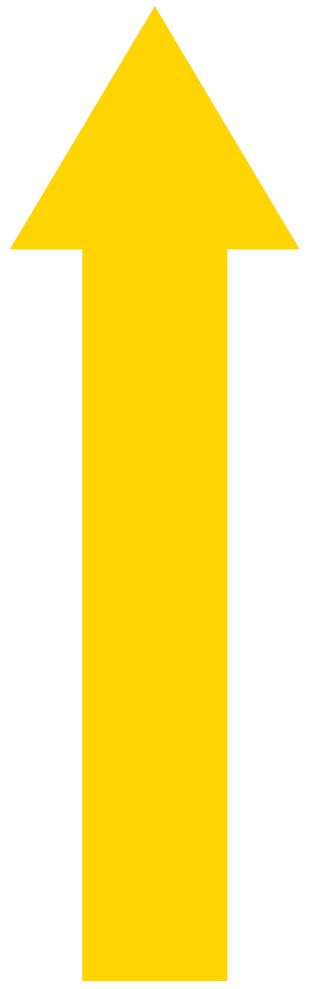

\section{A Fond Farewell to Dr. Jeff Kimpel, University of Oklahoma}

A special event was held at the University of Oklahoma (OU) campus recently to honor Dr. Jeff Kimpel's illustrious 30-year career. Among his many accomplishments, Dr. Kimpel was honored for his leadership during the development of the Meteorology Program at OU. Since 1981, Dr. Kimpel has served successively as the Director of the OU School of Meteorology, the
Dean of the OU College of Geosciences, the OU Senior Vice President and Provost, and as Director of NOAA's National Severe Storms Laboratory. A presentation, created by SGP site scientist Dr. Peter Lamb for the event, highlights Dr. Kimpel's role in the development of the ARM Southern Great Plains (SGP) site, which was established in 1992.

\section{Scientists Convene at SGP Site...continued from page 1}

Prior to this meeting, NASA technicians visited the SGP site to scout out locations for a network of $20-40$ rain gauges and approximately 25 disdrometers. A list of candidate sites was prepared, all located within approximately 10 kilometers of the SGP Central Facility. This dense network is designed to give important information on the variability of rain rates and rain drop-size distributions on the spatial scale of a space-based precipitation radar footprint. Testing of the instruments for this network is currently underway while leases with local landowners are being worked out.

\section{ARM Activity Corner...}

For more fun activities, please visit the Education section of our website!

\section{ACROSS}

2. When it's outside, it's important to wear a coat and hat!

3. Light reflects off of raindrops and puddles, and makes a colorful after it rains!

4. When the usually cold.

7. These white ice crystals are fun to play in! blows, it is

\section{DOWN}

1. The is actually a star that sits in the center of our solar system.

2. Some of these look big and fluffy, and some look thin and streaky, and when $t$ rains, the sky is filled with them!

3. This falls from the sky in drops - making puddles!

5. When water freezes, it makes

6. When it's outside, it's important to drink lots of water and wear sunscreen!

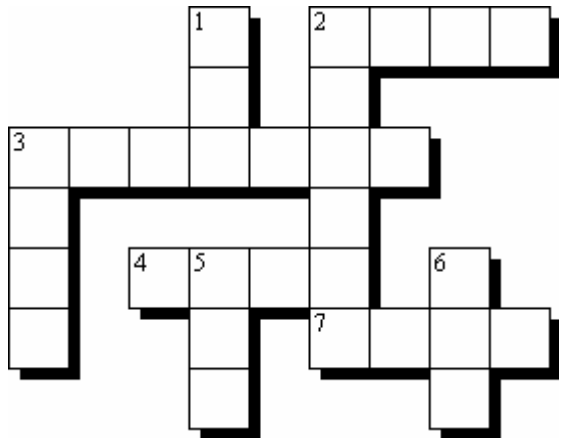

